\title{
The impact of omega-3 fatty acids on lung histopathology in mice model of chronic asthma
}

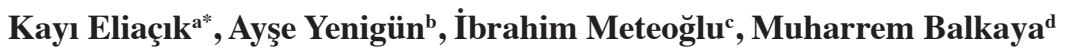 \\ ${ }^{a}$ Department of Pediatrics, Faculty of Medicine, Adnan Menderes University, Aydin, Turkey \\ ${ }^{b}$ Department of Pediatrics, Allergy Subdivision, Faculty of Medicine, Adnan Menderes University, Aydin, Turkey \\ ${ }^{c}$ Department of Pathology, Faculty of Medicine, Adnan Menderes University, Aydin, Turkey \\ ${ }^{d}$ Department of Physiology, Faculty of Veterinary Medicine, Adnan Menderes University, Aydin, Turkey
}

\section{ARTICLE INFO ABSTRACT}

\section{Article History}

$\begin{array}{ll}\text { Received } & 12 / 03 / 2014 \\ \text { Accepted } & 10 / 05 / 2014\end{array}$

\section{* Correspondence to:}

Kayı Eliaçık

Department of Pediatrics,

Tepecik Teaching and Research Hospital, Izmir, Turkey

e-mail: kayieliacik@gmail.com

Keywords:

Asthma

Experimental asthma

Mice model

Omega-3 fatty acids

\begin{abstract}
We aimed to determine the impact of the diet enriched with omega- 3 fatty acids, a potential anti-inflammatory agent, on chronic changes of asthma in a mice model. Therapeutic modalities have not yet been proved to be successful in reversing alreadyestablished chronic changes of airways in asthma. For this reason, interventions including dietary changes before the sensitization and remodeling period would prevent those changes. Six-week old female Balb/c mice $(n=18)$ were divided into two groups. During the development of chronic asthma model, mice in omega-3 fatty acid group received a diet enriched with omega- 3 fatty acids, whereas mice in the other group received a diet with saturated fatty acids. Balb/c mice were sensitized intraperitoneally in both groups using $10 \mu \mathrm{g} / 100 \mu \mathrm{l}$ of ovalbumin (OVA) and $1.5 \mathrm{mg} \mathrm{Al}(\mathrm{OH}) 3$ on days 1,14 and 21 . Primed mice were challenged by repeated intranasal instillation of $20 \mu \mathrm{g} / 10 \mu \mathrm{l}$ OVA three times a week. Mice were sacrificed and bronchoalveolar lavage fluid was obtained $24 \mathrm{~h}$ after the last challenge (day 77). The lungs were removed for histological examination. The omega-3 fatty acid group showed significantly reduced neutrophil percentage in bronchoalveolar lavage fluid. There was no statistically significant difference between the two groups in lymphocyte, macrophage and eosinophil percentages. The mean basement membrane thickness was less severe in the omega- 3 group than the saturated fatty acid group. There was no significant difference between the two groups for goblet cell numbers, subepithelial smooth muscle of airways, and bronchial-associated lymphoid tissue. The findings of this study suggest that consumption of omega-3 fatty acids would prevent some of the chronic changes of airways due to asthma. Future studies are needed to evaluate the potential preventive and therapeutic effects of omega-3 fatty acids in asthma.
\end{abstract}

J. Exp. Clin. Med., 2014; 31:95-98

\section{Introduction}

Therapeutic modalities of asthma have not yet been proved to be successful in reversing the already-established chronic changes of airways. Therefore, the notion of preventing or at least modifying the development of airway remodeling through dietary interventions would be beneficial.

The fatty acid composition of inflammatory and immune cells is sensitive to changes in the fatty acid composition of the diet. In particular, the proportion of different types of polyunsaturated fatty acids (PUFA) in these cells is readily changed, and this provides a link between dietary
PUFA intake, inflammation, and immunity. The n-6 PUFA arachidonic acid (AA) is the precursor of prostaglandins, leukotrienes and related compounds, all of which have important roles in inflammation and in the regulation of immunity (Calder, 2002).

Fish oil contains n-3 PUFA eicosapentaenoic acids (EPA) and docosahexaenoic acids (DHA). Feeding fish oil results in partial replacement of AA in cell membranes by EPA and DHA. This leads to decreased production of AA-derived mediators. In addition, EPA and DHA are substrates for cyclooxygenase and lipoxygenase and give rise to mediators 
that often have different biological actions or potencies than those formed from AA (James et al., 2000, Calder, 2001). A couple of animal studies indicate that fish oil can have potent effects on immune function and inflammatory cell responses (Jolly et al., 1997; Peterson et al., 1998a, 1998b).

Clinical trials about supplementing omega 3 -fatty acids to adults with established allergies and bronchial asthma have been generally disappointing. However, it is known that the immature immune system is highly susceptible to immunemodulation in the very early life (Calder et al., 2002). Until now, only a limited number of clinical studies were published about the beneficial effects of fish oil supplementation on asthma in postnatal period (Blümer and Renz, 2007).

In this study, we aimed to determine the impact of the diet enriched with omega-3 fatty acids, a potential antiinflammatory and immune-modulatory agent, on chronic changes of asthma in mice model.

\section{Materials and methods}

The Animal Ethics Committee of Adnan Menderes University approved the experimental procedures, and maintenance of animals in accordance with institutional guidelines.

\section{Mice}

Eighteen 6-week old female BALB/c mice (obtained from Cerrahpaşa Medical Biology Laboratories, Istanbul, Turkey) were maintained in the Laboratory Animals Breeding and Experimental Research Unit of Adnan Menderes University during the study between March-June 2008. Cages were placed into a ventilated cabinet in a quiet room on a 12:12 hour light/dark cycle and were kept at a constant room temperature $\left(24^{\circ} \mathrm{C}\right)$.

\section{Experimental diets}

After a 30-days acclimation period, mice were randomly assigned to diets containing lard or fish oil. Tap water and food were available ad libitum throughout the study. Nutritionally complete experimental diets (MBD Provender, Gebze, Kocaeli, Turkey) were based on the semi-purified AIN93G diet (Reeves, 1997). The original basal diet with lower fat was modified to contain $200 \mathrm{~g}$ fat $/ \mathrm{kg}$ diet by addition of fish and corn oils or lard, while maintaining the same nutrient to energy ratio. The test diet contained $18 \%$ mackerel fish oil (a gift from Orzax Medicine, Quincy, USA) and 2\% corn oil to prevent essential fatty acid (18:2n-6) deficiency. The higher than usual fat content of this experimental diet allows a greater level of n-3 PUFA enrichment with a widely used fish oil source of these fatty acids, i.e., mackerel fish oil. The control diet contained 20\% lard. Both lard and fish oils were stabilized with a synthetic antioxidant $(0.2 \mathrm{~g} / \mathrm{kg}$ tert-butylhydroquinone). Other diet ingredients included (per $\mathrm{kg}$ of diet): $354.6 \mathrm{~g}$ corn starch, $230 \mathrm{~g}$ casein, $100 \mathrm{~g}$ sucrose, 57.4 $\mathrm{g}$ fiber, 40.2 g AIN-93 mineral mix, $11.2 \mathrm{~g}$ AIN-93 vitamin mix, $3.4 \mathrm{~g}$ L-cysteine, $2.9 \mathrm{~g}$ choline bitartate, and $200 \mathrm{~g}$ fat. The fatty acid composition of these diets has been previously reported by Irons et al (2003).

\section{Study design}

Mice were divided into two equal size groups by their feeding modality (Table 1). During the development of chronic asthma model, mice in omega-3 fatty acid group received diet
Table 1. Repartition of each fatty acid in the two diet groups (gram per 100 grams of lipids)

\begin{tabular}{lcc} 
Fatty acid & ( ) 3 diet & SF Diet \\
\hline C16:0 (PA) & 9.0 & 26.0 \\
C18:0 (SA) & 3.0 & 8.0 \\
Total of saturated & 12.0 & 34.0 \\
MUFA oleic acid & 45.0 & 30.0 \\
C18:2 $\omega 6$ (LA) & 23.0 & 25.0 \\
C18:3 $\omega 3$ (ALA) & 10.0 & 0.0 \\
C18:3 $\omega$ 6 (GLA) & 3.0 & 0.0 \\
C18:4 $\omega$ 3 (STA) & 2.0 & 0.0 \\
C20:4 $\omega$ 6 (AA) & 0.5 & 11.0 \\
C20:5 $\omega 3$ (EPA) & 5.0 & 0.0 \\
C22:6 $\omega 3$ (DHA) & 2.0 & 0.0 \\
Total of PUFA & 43.0 & 27.0 \\
\hline
\end{tabular}

MUFA: Mono-unsaturated fatty acid; PA: Palmitic acid; SA: Stearic acid; LA: Linoleic acid; AA: Arachidonic acid; ALA: $\alpha$-linolenic acid; GLA: $\gamma$-linolenic acid; STA: Stearidonic acid; EPA: Eicosapentaenoic acid; DHA: Docosahexaenoic acid; PUFA: Polyunsaturated fatty acid; SF: Control diet with saturated fatty acids.

enriched with omega-3 fatty acids, whereas mice in control group received a diet enriched with saturated fatty acids.

\section{Establishment of chronic asthma model}

$\mathrm{Balb} / \mathrm{c}$ mice were sensitized intraperitoneally in both groups using $10 \mu \mathrm{g} / 100 \mu \mathrm{l}$ of ovalbumin (OVA) and $1.5 \mathrm{mg} \mathrm{Al}$ $(\mathrm{OH}) 3$ on days 1,14 and 21 . Primed mice were challenged by repeated intranasal instillation of $20 \mu \mathrm{g} / 10 \mu \mathrm{l}$ OVA three times a week during 8 weeks.

\section{Histopathological examination}

Mice were sacrificed and bronchoalveolar lavage fluid (BALF) was obtained by flushing the lung 3 times with $1 \mathrm{ml}$ PBS 24 $\mathrm{h}$ after the last challenge (day 77). Slides were prepared by cytocentrifugation (Cytospin 3, Shandon Scientific, Runcorn, Cheshire, UK) and stained with May-Grunwald-Giemsa. Differential cell counts were made on two different slides for each animal, counting at least 200 inflammatory cells per slide, and the means of two slides were recorded.

Lung tissues were fixed in $10 \%$ phosphate-buffered formalin for 24 hours and embedded in paraffin wax. Sections (2 to $3 \mathrm{~mm}$ ) were cut and stained with hematoxylineosin (H\&E) and periodic acid-Schiff (PAS). The stained sections were visualized by light microscopy and examined for thickness of epithelia, basement membrane, bronchialassociated lymphoid tissue, subepithelial smooth muscle and goblet cell hyperplasia. The density of changes was scored in relative units $(\mathrm{RU})$, with $0=$ no, $1=$ weak, $2=$ moderate, and $3=$ strong.

\section{Statistical analysis}

SPSS 15 for Windows ${ }^{\circledR}$ was used for statistical analysis of the data. Mann-Whitney $U$ test was used to compare data between two groups. A p value of less than 0.05 was considered to be significant.

\section{Results}

Three mice from the omega-3 fatty acid group and six mice from the control group died during the study. Compared with the controls, the omega-3 fatty acid group showed significantly 
reduced neutrophil percentage in BALF $(p=0.024)$. Although the animals fed on fish oil-containing diet had higher mean number of lymphocytes than that of the controls, the difference between the two groups was not found to be statistically significant $(\mathrm{p}=0.085)$. The subepithelial smooth muscle thickness of the airways was higher in the group fed on lard-containing diet compared with that of the fish-oil group, but this was also statistically insignificant $(\mathrm{p}=0.083)$. The mean percentages of macrophages and eosinophil leukocytes as well as the goblet cell numbers and bronchialassociated lymphoid tissues were similar in animals of both groups ( $\mathrm{p}>0.05)$. The comparison of the two groups showed statistically significant difference in basement membrane thickness. The mean basement membrane thickness of animals fed on a lard-enriched diet was significantly greater than that of animals fed on a fish oil-enriched diet $(\mathrm{p}=0.038)$.

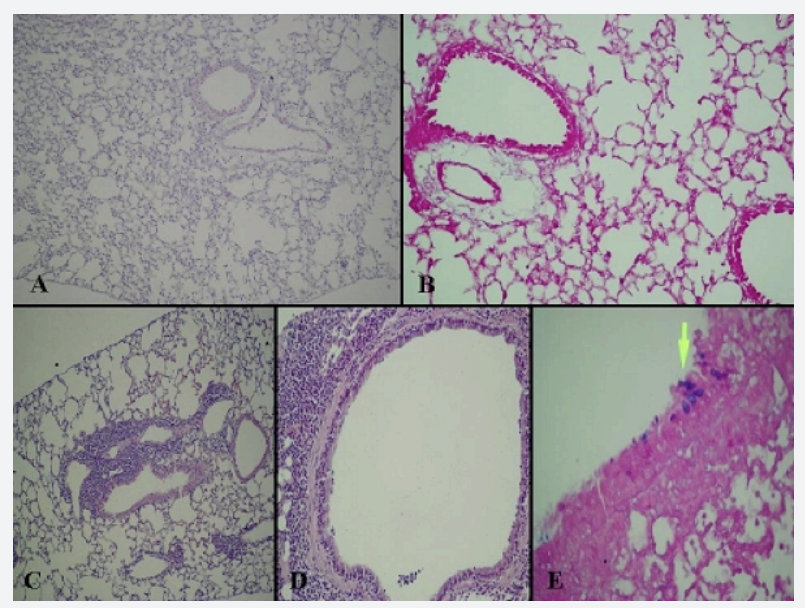

Fig. 1. A: Normal bronchioles (Omega group, Hematoxylin \& Eosin, $\mathrm{x} 40$ )

B: Omega group. No goblet cell (Periodic acidSchiff+Alcain Blue, $\mathrm{x} 200$ )

C: Thick BALT (SF group, Hematoxylin \& Eosin, $\mathrm{x} 100$ )

D: BALT, muscle and bazal membrane thickening (SF group, Hematoxylin \& Eosin, x200)

E: SF group Goblet cells (Periodic acid-Schiff+Alcain Blue, $x 400$ )

Table 2. Structural changes in the airways

\begin{tabular}{lcccc}
\hline & $\begin{array}{c}\text { Goblet } \\
\text { cell } \\
\text { hyperplasia }\end{array}$ & $\begin{array}{c}\text { Muscle } \\
\text { thickening }\end{array}$ & $\begin{array}{c}\text { Basal } \\
\text { membrane } \\
\text { thickening }\end{array}$ & BALT \\
\hline$\omega 3_{1}$ & 0 & 1 & 1 & 1 \\
$\omega 3_{2}$ & 1 & 1 & 0 & 2 \\
$\omega 3_{3}$ & 1 & 0 & 1 & 1 \\
$\omega 3_{4}$ & 2 & 1 & 0 & 2 \\
$\omega 3_{5}$ & 0 & 0 & 1 & 1 \\
$\omega 3_{6}$ & 1 & 0 & 0 & 1 \\
$\mathrm{SF}_{1}$ & 1 & 1 & 2 & 2 \\
$\mathrm{SF}_{2}$ & 2 & 2 & 1 & 1 \\
$\mathrm{SF}_{3}$ & 1 & 1 & 2 & 2 \\
\hline $\mathrm{Se}_{3}$ & 1 & 1 & \\
\hline
\end{tabular}

Sections stained with hematoxylin-eosin (H\&E) or periodic acid-Schiff (PAS). The stained sections were examined for inflammatory changes and goblet cell metaplasia.

The density of changes was scored in relative units (RU) with $0=$ no, $1=$ weak, $2=$ moderate, and $3=$ strong goblet cell hyperplasia

$\omega$ 3: Omega-3 fatty acid group; SF: Saturated fatty acid group
All of the different-sized airways of the omega-3 fatty acid group were compared with the lard-enriched group based on the same parameters. This comparison revealed that the difference in basement membrane thickness is the same in all small, medium and large-sized airways in the omega- 3 fatty acid group (Fig. 1, Table 2)

\section{Discussion}

The objective of this study was to determine the effects of a diet enriched either with n-3 PUFAs or saturated fatty acids on structural changes of airways in a chronic mice model of asthma.

Preliminary studies demonstrated almost always an increase in the numbers of neutrophils, eosinophils, macrophages and lymphocytes in the respiratory system of animals sensitized via OVA (Nabe et al., 2005; Nabe et al., 2011; Yang et al., 2011; Brandenberger et al., 2013; Kim et al., 2013). In this study, there was no difference between the two groups for eosinophilia and macrophage, with a slight difference in the number of lymphocytes $(\mathrm{p}=0.085)$. However, there was a significant difference in neutrophils due to their decrease in BALF of omega-3 PUFA group ( $\mathrm{p}=0.024)$. This finding demonstrates that omega- 3 fatty acids have phasedependent anti-inflammatory effects, affecting the early phase of asthma by reducing the number of neutrophils.

Airway mucosa remodeling is the consequence of chronic inflammatory processes and represents the final stage of asthma (Fahy et al., 2000). Histological examination of the lung tissue did not reveal any difference for goblet cells and bronchia-associated lymphoid tissues. However, the comparison of the two groups showed a slightly increased subepithelial smooth muscle thickness of airways, and a statistically significant increase in basement membrane thickness in the omega- 3 group $(\mathrm{p}=0.083$ and $\mathrm{p}=0.038$, respectively). This data indicate that dietary omega-3 fatty acids could reduce some of the structural chronic changes seen in asthma.

It is now well known that consumption of fish oil containing omega-3 fatty acids reduces the risk of many human diseases (Sidhu, 2003). Dietary lipid manipulation may affect different immune parameters and the immunemodulation induced by dietary fatty acids may be beneficial in inflammatory diseases. A dietary immune modulation with omega-3 polyunsaturated fatty acid should represent an interesting alternative to immune suppressive molecules, like corticosteroids, which concomitantly has many undesired side-effects (Dahl, 2006). In this study, two different diet groups were used (Table 1). One diet was dominated by EPA and DHA which have less potential inflammatory products such as PGE3 and LTB5. Nevertheless, EPA and DHA act as a competitive inhibitor of AA conversion to the proinflammatory key mediators PGE2 and LTB4. And, the other diet was dominated by saturated fatty acids and arachidonic acid, which give rise to PGE2 and LTB4 (James et al., 2000).

Some studies have focused on the anti-inflammatory effects of omega-3 fatty acids on asthma (Blümer et al., 2005). Wallace et al. (2001) reported that omega-3 fatty acids are effective on T-helper 1 cells and eicosanoid metabolism. Korotkova et al. (2004a; 2004b) showed that omega-3 fatty acid-enriched diet in pregnant rats suppressed the allergic reactions of their offsprings. Yokoyama and co-workers 
showed that nebulized DHA has anti-inflammatory effects on an acute asthma model in mice (Yokoyama et al., 2000).

In the future, it will be necessary to develop preventive strategies as well as strategies which specifically and sufficiently interfere in structural changes of the airways, since none of the currently available therapies are able to prevent or stop the beginning of airway remodeling (Wegmann and Renz, 2005).

In addition to previous studies evaluating the inhibitory effects of omega-3 fatty acids on acute asthma, the current study is the first to determine the immune-modulatory effects of dietary fatty acids on the structural changes of chronic asthma and provides an evidence of diminished neutrophil production in inflammation process.

Therefore, the notion of preventing or at least modifying the development of airway remodeling by supplementing with omega-3 PUFAs in asthma seems to be a promising approach. However, there is an increasing need for future studies to evaluate the potential benefits of omega-3 fatty acids in asthma.

\section{REFERENCES}

Blümer, N., Herz, U., Wegmann, M., Renz, H., 2005. Prenatal lipopolysasaccharide-exposure prevents allergic sensitization and airway inflammation, but not airway hyperresponsiveness in a murine model of experimental asthma. Clin. Exp. Allergy. 35, $397-402$.

Blümer, N., Renz, H., 2007. Consumption of omega-3-fatty acids during perinatal life: Role in immuno-modulation and allergy prevention. J. Perinat. Med. 35, 12-18.

Brandenberger, C., Rowley, N.L., Jackson-Humbles, D.N., Zhang, Q., Bramble, L.A., Lewandowski, RP., Wagner, J.G., Chen, W., Kaplan, B.L., Kaminski, N.E., Baker, G.L., Worden, R.M., Harkema, J.R., 2013. Engineered silica nanoparticles act as adjuvants to enhance allergic airway disease in mice. Particle and Fibre Toxicology. 10, 26. doi: 10.1186/1743-8977-10-26.

Calder, PC., 2002. Dietary modification of inflammation with lipids. Proc. Nutr. Soc. 61, 345-358.

Calder, PC., 2001. Polyunsaturated fatty acids, inflammation, and immunity. Lipids. 36, 1007-1024.

Calder, PC., Yaqoob, P., Thies, F., Wallace, F.A., Miles, E.A., 2002. Fatty acids and lymphocyte functions. Br. J. Nutr. 87, 31-48.

Dahl, R., 2006. Systemic side effects of inhaled corticosteroids in patients with astma. Respir. Med.100, 1307-1317.

Fahy, J.V., Corry, D.B., Boushey, H.A., 2000. Airway inflammation and remodeling in asthma. Curr. Opin. Pulm. Med. 6, 15-20.

Irons, R., Anderson, M.J., Zhang, M., Fritsche, K.L., 2003. Dietary fish oil impairs primary host resistance against Listeria monocytogenes more than the immunological memory response. J. Nutr. 133, 1163-1169.

James, M.J., Gibson, R.A., Cleland, L.G., 2000. Dietary polyunsaturated fatty acids and inflammatory mediator production. Am. J. Clin. Nutr. 71, 343-348.

Jolly, C.A., Jiang, Y.H., Chapkin, R.S., McMurray, D.N., 1997. Dietary (n-3) polyunsaturated fatty acids suppress murine lymphoproliferation, interleukin-2 secretion and the formation of diacylglycerol and ceramide. J. Nutr. 127, 37-43.

Kim, M.S., Cho, K.A., Cho, Y.J., Woo, S.Y., 2013. Effects of interleukin-9 blockade on chronic airway inflammation in murine asthma models . Allergy. Asthma. Immunol. Res. 5, 197-206. doi: 10.4168/aair.2013.5.4.197.

Korotkova, M., Telemo, E., Hanson, L.A., Strandvik, B., 2004a. Modulation of neonatal immunological tolerance to ovalbumin by maternal essential fatty acid intake. Pediatr. Allergy. Immunol. 15, 112.

Korotkova, M., Telemo, E., Yamashiro, Y., Hanson, L.A., Strandvik, B., 2004b. The ratio of n-6 to n-3 fatty acids in maternal diet influences the induction of neonatal immunological tolerance to ovalbumin. Clin. Exp. Immunol. 137, 237.

Nabe, T., Hosokawa, F., Matsuya, K., Morishita, T., Ikedo, A., Fujii, M., Mizutani, N., Yoshino, S., Chaplin, D.D., 2011. Important role of neutrophils in the late asthmatic response in mice. Life. Sci. 88, 1127-1135. doi: 10.1016/j.lfs.2011.04.003.

Nabe, T., Zindl, C.L., Jung, Y.W., Stephens, R., Sakamoto, A., Kohno, S., Atkinson, T.P., Chaplin, D.D., 2005. Induction of a late asthmatic response associated with airway inflammation in mice. Eur. J. Pharmacol. 521, 144-155.

Peterson, L.D., Jeffery, N.M., Thies, F., Sanderson, P., Newsholme, E.A., Calder, P.C., 1998a. Eicosapentaenoic and docosahexaenoic acids alter rat spleen leukocyte fatty acid composition and prostaglandin E2 production but have different effects on lymphocyte functions and cell-mediated immunity. Lipids. 33, 171-180.

Peterson, L.D., Thies, F., Sanderson, P., Newsholme, E.A., Calder, P.C., 1998b. Low levels of eicosapentaenoic and docosahexaenoic acids mimic the effects of fish oil upon rat lymphocytes. Life. Sci. 62, 2209-2217.

Reeves, P.G., 1997. Components of the AIN-93 diets as improvements in the AIN-76A diet. J. Nutr. 127, 838-841.

Sidhu, K.S., 2003. Health benefits and potential risks related to consumption of fish or fish oil. Regul. Toxicol. Pharmacol. 38, 336-344.

Wallace, F.A., Miles, E.A., Evans, C., Stock T.E, Yaqoob P, Calder P.C, 2001. Dietary fatty acids influence the production of Th1-but not Th2-type cytokines. J. Leukoc. Biol. 69, 449-455.

Wegmann, M., Renz, H., 2005. Animal models of experimental asthma. Ernst. Schring. Res. Found. Workshop. 50, 69-87.

Yang, Y., Hsu, H., Wang, K., Han, C., Chen, C., Chen, C., Ko, W., 2011. Hesperetin-7,3'-O-dimethylether selectively inhibits phosphodiesterase 4 and effectively suppresses ovalbumin-induced airway hyperresponsiveness with a high therapeutic ratio. J. Biomed. Sci. 18, 84. doi: $10.1186 / 1423-0127-18-84$.

Yokoyama, A., Hamazaki, T., Ohshita, A., Kohno, N., Sakai, K., Zhao, G.D., Katayama, H., Hiwada, K., 2000. Effect of aerosolized docosahexaenoic acid in a mouse model of atopic asthma. Int. Arch. Allergy. Immunol. 123, 327-332 